\title{
Morphology and Crystallization of Polypropylene/Microfibrillated Cellulose Composites
}

\author{
Sarit Thanomchat \\ Department of Materials Science, Faculty of Science, Chulalongkorn University, Bangkok, Thailand \\ Chair of Composite Engineering, University of Kaiserslautern, Kaiserslautern, Germany
}

\author{
Kawee Srikulkit \\ Department of Materials Science, Faculty of Science, Chulalongkorn University, Bangkok, Thailand \\ Center of Excellence on Petrochemical and Materials Technology, Chulalongkorn University, Thailand
}

\author{
Buncha Suksut \\ Chair of Composite Engineering, University of Kaiserslautern, Kaiserslautern, Germany \\ Research Center OPTIMAS, University of Kaiserslautern, Kaiserslautern, Germany
}

\author{
Alois Karl Schlarb* \\ Chair of Composite Engineering, University of Kaiserslautern, Kaiserslautern, Germany \\ Research Center OPTIMAS, University of Kaiserslautern, Kaiserslautern, Germany \\ INM - Leibniz Institute for New Materials, Saarbrucken, Germany \\ * Corresponding author. E-mail: alois.schlarb@mv.uni-kl.de \\ Received: 21 August 2014; Accepted: 16 September 2014; Published online: 2 October 2014 \\ (C) 2014 King Mongkut's University of Technology North Bangkok. All Rights Reserved.
}

\begin{abstract}
Microfibrillated cellulose (MFC) was prepared by controlling the re-precipitation of cellulose prepared in the mixture form of $\mathrm{NaOH/Urea} \mathrm{solubilized} \mathrm{microcrystalline} \mathrm{cellulose} \mathrm{(MCC)} \mathrm{and} \mathrm{starch.} \mathrm{The} \mathrm{cellulose}$ re-precipitation was carried-out in an $\mathrm{HCl}$ bath, resulting in a MFC form having relatively lower crystallinity than MCC. The XRD pattern of MFC indicated the partially crystalline structure arising from the imperfect orientation of a cellulose chain obstructed by a starch molecule in the precipitation step. Interestingly, the MFC morphology exhibited a web-like structure with a diameter in the range of 10-20 $\mathrm{nm}$. The water retention value of MFC was extraordinarily high due to its extremely small diameter having high surface area. Further, surface silanization of MFC with organosilane was carried out. Then, the modified MFC was melt-mixed with polypropylene (PP) matrix via a simple melt mixing technique. The morphology and crystallization of the PP/MFC composites were measured. The morphology of organosilane treated MFC exhibited agglomeration of 10 microns in diameter with layered structures arising from the packing of microfibrils. The FTIR spectra showed hydrophobic characteristics of treated MFC observed by the disappearance of original cellulose hydroxyl group and bound water. The crystallinity of treated MFC increased when compared to the untreated MFC, indicating that cellulose chains of unmodified MFC underwent re-orientation occurring in the modification step due to its high crystallinity characteristic. For the PP/MFC-composite containing MFC loading, faster crystallization and higher spherulite growth rate, in case of higher MFC loading, were observed. In addition, the spherulite size decreased with an increase in the crystallization temperature. However, the degree of crystallinity was fairly independent on the MFC-loading. Therefore it can be concluded that the addition of MFC might enable shorter
\end{abstract}

Please cite this article as: S. Thanomchat, K. Srikulkit, B.Suksut, and A.K. Schlarb, "Morphology and Crystallization of Polypropylene/Microfibrillated Cellulose Composites," KMUTNB Int J Appl Sci Technol, Vol.7, No.4, pp. 23-34, (2014), http://dx.doi.org/10.14416/j.ijast.2014.09.002 
cycle times, resulting in cheaper processing cost in a view point of polymer processing.

\section{Keywords: Composites, Microfibrillated cellulose, Morphology, Crystallization}

\section{Introduction}

Polypropylene (PP) is the most widely used and fastest growing classes of thermoplastic polymers found in various industries. It exhibits a good balance between physical and mechanical properties as well as an ease of processability at a relatively low cost. However, the usage of PP is still limited by its comparatively low modulus and stiffness when compared to engineering plastics [1]. To overcome these limitations, an incorporation of reinforcing fibers such as glass fibers/carbon fibers or fillers such as calcium carbonate [2], titanium dioxide, [3] and silicon dioxide, [4-6], is the most popular method. Moreover, several attempts have been used either natural fibers [7] or synthetic fibers [8] to enhance the properties of polymer. Polymer/ cellulose composites are interesting branches in the field of composite materials [9-15]. Chemically, the structure of cellulose consists of anhydroglycoside repeating units (AGU)). Interestingly, cellulose can be found in a variety of different forms such as microcrystalline cellulose, microfibrillated cellulose and nanocrystalline structures. Microcrystalline cellulose (MCC) is the most well-known form which has been widely investigated as a potential reinforcing filler for polymers. According to the literature, MCC is easily prepared by reacting cellulosic materials (cotton or wood pulp) with an aqueous solution of strong mineral acids preferably hydrochloric acid at boiling temperature for a period of time. A hydrolysis reaction removes the amorphous cellulose, leaving microcrystalline cellulose existing in a rod shaped particle with a micron-sized range particle [16,17]. Recently, microfibrillated cellulose, MFC, also called cellulose microfibrils, microfibrillar cellulose or nanocellulose, has attracted a great attention in the field of polymer nanocomposites. When compared to MCC, MFC has an interesting characteristic including a high aspect ratio, a rigid web-like structure, high strength and stiffness as well as a high surface area. Therefore, polymer nanocomposites containing MFC could offer superior performance when compared to conventional polymer composites such as higher $T_{c}$ (crystallization temperature), higher modulus $\mathrm{E}$, better barrier properties and lighter weight [18-20]. Apart from nanocomposite fields, MFC can be employed as thickening agent, emulsifier or additive in food, paints, coatings, cosmetics and medical products [21].

Structurally, MFC is consist of elementary fibrils aggregation with a diameter from 20 to $60 \mathrm{~nm}$ and a length of several micrometers [22,23].

The conventional methods of MFC extraction from cellulosic materials typically involve mechanical treatments such as homogenizing, microfluidizing, cryocrushing or grinding. However, the drawbacks of these techniques are high energy consumption and low output. To solve this problem, pretreatments such as enzymatic treatments, 2,2,6,6-tetramethyl1-piperidinyloxy (TEMPO) mediated oxidation and carboxymethylation have been developed to overcome the strong cohesive hydrogen bonding among adjacent microfibrils $[22,23]$.

In this work, the preparation of MFC was modified based on dissolution techniques. These techniques are commercially employed in the rayon process and tencel process. Solvent systems such as aqueous inorganic complexes (e.g. cuoxam, cuam, cuen), aqueous bases (e.g. $10 \% \mathrm{NaOH}$ ), mineral acids, melts of inorganic salt hydrate, N, N-dimethylacetamide/LiCl, dimethylsulfoxide/triethylamine/ $\mathrm{SO}_{2}, \mathrm{NH}_{3} / \mathrm{NH}_{4} \mathrm{SCN}, \mathrm{CF}_{3} \mathrm{COOH}, \mathrm{HCOOH}$ and $\mathrm{N}$, $\mathrm{N}$-dimethylformamide $/ \mathrm{N}_{2} \mathrm{O}_{4}$ have been selected for dissolving the cellulose fiber [24,25]. However, some solvents were tried a laboratory only due to the volatility, toxicity and high cost [26]. Common aqueous $\mathrm{NaOH}$ systems including $\mathrm{NaOH} /$ urea and $\mathrm{NaOH} /$ thiourea solution are widely used for cellulose dissolution. In practice, cellulose could be dissolved in a pre-cooled solution containing a $7 \mathrm{wt} \% \mathrm{NaOH} /$ $12 \mathrm{wt} \%$ urea system [27-29].

In our work, MFC from cotton source was prepared by dissolution of cotton $\mathrm{MCC}$ in a $\mathrm{NaOH} /$ urea system. Then, alkali solubilized starch solution was added to obtain a cellulose/starch miscible mixture. After that, controlled precipitation in an $\mathrm{HCl}$ solution was conducted to convert solubilized cellulose into MFC which was evenly dispersed in the starch matrix. Upon standing for $6 \mathrm{~h}$, the starch matrix acting as 
anti-coagulating agent was slowly hydrolyzed by acid hydrolysis, leaving extremely fine MFC. However, the direct addition of hydrophilic MFC into a hydrophobic polymer led to extremely poor dispersibility due to MFC hard aggregation. Therefore, a surface modification of the MFC with an organosilane was carried out. The organosilane treated MFC was then incorporated into polypropylene.

The aim of our work was to study the morphology of a newly prepared MFC and its effect on the crystallization behavior of PP/MFC-composites which was compounded via a simple melt mixing technique.

\section{Experimental}

\subsection{Materials}

Microcrystalline cellulose (MCC) obtained from acid hydrolysis of cotton fabric waste, sodium hydroxide pellet (Ajax finechem, Pty., Ltd.), urea (Ajax finechem, Pty., Ltd.) hydrochloric acid 37\% (QRëc), hexadecyltrimethoxysilane (Dynasylan 9116, Evonik), glacial acetic acid (VWR), isopropanol and food grade tapioca starch flour were used for the MFC preparation.

As matrix material polypropylene PP (PP HD120 $\mathrm{MO}$, Borealis GmbH, Burghausen, Germany) was used as received by Borealis.

\subsection{MFC preparation}

\subsubsection{Microcrystalline cellulose preparation}

MCC was prepared by acid hydrolysis of cotton fabric according to the method of Rattanakamnuan et al [30]. The cotton fabric was cut into approximately $2 \mathrm{~cm} \times 2 \mathrm{~cm}$ pieces and then heated and stirred in $2.5 \mathrm{~N} \mathrm{HCl}$ for $2 \mathrm{~h}$. At the end of the reaction, microcrystalline cellulose was filtered and washed until the $\mathrm{pH}$ value became neutral. The MCC was then dried in an oven at $60^{\circ} \mathrm{C}$ over night.

\subsubsection{Microfibrillated cellulose preparation (ref. Thai patent no.1301002478 (pending))}

A $5 \% \mathrm{w} / \mathrm{v}$ MCC solution was prepared by adding MCC into cooled $\mathrm{NaOH} / \mathrm{urea} / \mathrm{H}_{2} \mathrm{O}$ (7:12:81 by weight) at $-5.0^{\circ} \mathrm{C}$ and stirred continuously to obtain a slurry mixture. The slurry mixture was kept at $-5.0^{\circ} \mathrm{C}$ until the MCC particles were completely dissolved and the solution became transparent. In parallel a $5 \% \mathrm{w} / \mathrm{v}$ starch solution was prepared by dissolving starch in water, followed by dropping a $5 \% \mathrm{w} / \mathrm{v} \mathrm{NaOH}$ solution to gelatinize the starch until the solution became gel-like and transparent. Then, the starch solution was added to the MCC solution and stirred to obtain a homogeneous MCC/starch solution. MFC was obtained by precipitating the cellulose/starch solution in an $\mathrm{HCl}$ solution. In acidic media, the MFC colloid was formed and stabilized by starch gel as an anti-coagulating agent. Upon standing for $6 \mathrm{~h}$, the starch part was hydrolyzed by a strong acid, leaving the MFC dispersion. Filtration and washing with distilled water were carried out to remove $\mathrm{HCl}$ until the $\mathrm{pH}$-value became 5. Then solvent exchange with methanol was conducted. For comparison purposes regenerated MCC was prepared without the starch solution by dissolution of MCC in a $\mathrm{NaOH} /$ Urea solution by the same method as MFC

\subsubsection{Surface modification of $M F C$}

MFC was modified by Dynasylan 9116 (hexadecyltrimethoxysilane). $150 \mathrm{ml}$ of dynasylan 9116: isopropanol: $\mathrm{H}_{2} \mathrm{O}$ mixture (1:1:1 by volume) was added to $100 \mathrm{~g}$ of MFC and stirred continuously. Acetic acid was dropped into the mixture until the $\mathrm{pH}$ was 3 to activate the silanization reaction. The mixture had been continuously stirred for $3 \mathrm{~h}$ at ambient temperature and then dried at $60^{\circ} \mathrm{C}$ for $24 \mathrm{~h}$. The dried organosilane treated MFC was ground and sieved by sieve no. 400 mesh.

\section{$2.3 P P / M F C$ composite preparation}

\subsubsection{Melt Mixing}

PP Pellets were wrapped in a polyimide film, heated up to $200^{\circ} \mathrm{C}$ on a hot plate and kept there for 2 minutes until the PP was molten completely. The molten material was then manually flattened, removed quickly from the hot plate and quenched to a thin film of about $0.7 \mathrm{~mm}$ on a cold steel surface. Subsequently organosilane treated MFC powder was applied to the top of the solid PP-film and the stack was re-molten on the hot plate again. In the molten state the stack was fold up several times to prepare a composite with homogeneous dispersion and distribution of the filler. This thickness of the final film was roughly $0.7 / \pm 0.2 \mathrm{~mm}$. With this 
procedure, two different loading levels ( 1 vol.\% and 4 vol.\%) of PP/ MFC-composites were prepared. The procedure was also applied to the neat PP in order to guarantee the same thermal history in every specimen.

\subsubsection{Thin film preparation}

A small piece of material was cut from the solid PP-film, which has been prepared according to 2.3.1 and treated equally as described in section 2.3.1. However, to prepare a thin film the molten specimen was compressed and quenched to finally get a film thickness of about $25 / \pm 5 \mu \mathrm{m}$.

\subsubsection{Chemical etching}

A piece of specimen as prepared in accordance to section 2.3.1 was chemically etched [31,32] with a solution consisting of $0.7 \%$ weight/volume potassium permanganate crystals and a mixture of $2: 1$ by volume $98 \%$ sulphuric acid and $85 \%$ phosphoric acid as described by Schlarb et al [5] in detail.

\section{Characterizations}

\subsection{Characterizations of MFC and organosilane treated MFC}

\subsubsection{Water Retention Value, WRV}

The water retention value of MFC was measured to identify the water content held by MFC. A certain amount of MFC was dispersed in deionized water in a centrifuge tube for $24 \mathrm{~h}$ at ambient temperature and then the sample was centrifuged at $30 \mathrm{~Hz}$ for 20 min. The wet samples were weighed, $\mathrm{W}_{\mathrm{w}}$ and dried in an oven for $24 \mathrm{~h}$ at $105^{\circ} \mathrm{C}$, then the dry weight was recorded, $\mathrm{W}_{\mathrm{d}}$ [33]. The WRV was calculated by the following formula:

$W R V=\frac{W_{w}-W_{d} \times 100}{W_{d}}$

\subsubsection{Morphology}

The morphology of MFC was investigated by a field (cold cathode) emission scanning electron microscope
(FE-SEM. Hitachi S-4800, Japan). Carbon (thickness: ca. $5 \mathrm{~nm}$ ) was used as a conducting layer. A transition electron microscope (TEM, TECNAI T20 G2, FEI and Netherlands) was employed to investigate morphology of MFC. A drop of $10 \mu \mathrm{l}$ of re-dispersed MFC in water was added onto a carbon-coated electron microscopy grid and the excess liquid was absorbed by filter paper. The samples were negatively stained with $2 \%$ uranyl acetate. The morphology of organosilane treated MFC was observed by a scanning electron microscope (JSM $6460 \mathrm{LV}$, Jeol, Japan) with accelerating voltage $15 \mathrm{kV}$. The sample was dropped on a carbon tape and coated with gold by a sputter coater.

\subsubsection{Dispersion of $M F C$}

The dispersion of organosilane treated MFC in toluene was investigated by an optical microscope (ECLIPSE LV100, Nikon GmbH, Düsseldorf). The sample was dispersed in toluene and then dropped on a glass slide and covered by cover slip. Two modes of optical microscopy including reflection light mode and transmission light mode without polarized light were used for investigation.

\subsubsection{Particles Size Distribution}

Particle size distribution of organosilane treated MFC powder was investigated by a static light scattering technique using a laser particle size analyzer (LA-950, HORIBA, Japan). The powder was dispersed in toluene and then dropped into a sample flow cell before measurement. Toluene was used as a medium standard solution in a flow cell.

\subsubsection{X-Ray Diffraction}

The crystallinity of MCC, regenerated MCC, MFC and organosilane treated MFC was characterized by an $\mathrm{X}$-ray diffractometer (D8 advance, Bruker, Germany) by reflection method using a $\mathrm{Cu} \mathrm{K \alpha}$ target at $40 \mathrm{kV}$ with the diffraction angle range from 5 to $40^{\circ}$.

\subsubsection{Fourier transform infrared spectroscopy}

The functional groups of MFC and organosilane treated MFC were investigated by a Fourier transform infrared spectrometer (Nicolet 6700, Thermo Electron 
Corporation) using transmission mode. A sample for characterization was prepared by $\mathrm{KBr}$ pellet technique.

\subsection{Characterizations of PP/MFC composites}

\subsubsection{Optical microscopy}

In order to reveal the dispersion and distribution of the materials, thin films (see 2.3.2) were applied onto a glass substrate and covered by a cover slip. Then the materials were analyzed under transmitted light using an optical microscope (ECLIPSE LV100, Nikon $\mathrm{GmbH}$, Düsseldorf).

The solidification process of the materials as obtained from non-isothermal crystallization and the spherulite growth rate as obtained from isothermal crystallization were observed by the same polarized light microscope equipped with a heating stage (LTS 420, Linkam Scientific Instruments, Surrey). The development of the spherulitic structure was recorded by a CCD camera.

For the crystallization studies, the specimens were heated to $200^{\circ} \mathrm{C}$ at a rate of $20 \mathrm{~K} / \mathrm{min}$ and held for $2 \mathrm{~min}$ at this temperature. Then, for non-isothermal crystallization the material was cooled to $30^{\circ} \mathrm{C}$ at $20 \mathrm{~K} / \mathrm{min}$.

For isothermal crystallization, the specimens were cooled at the rate of $20 \mathrm{~K} / \mathrm{min}$ to various given crystallization temperatures $\left(130^{\circ} \mathrm{C}, 132^{\circ} \mathrm{C}\right.$ and $\left.134^{\circ} \mathrm{C}\right)$ and held constant until completion of crystallization was observed. The radial growth rate of the spherulites was calculated using the recorded movies to measure the size of PP spherulites as a function of time. Five spherulites of each specimen were characterized.

Each crystallization experiment was repeated at least 2 times in order to verify the reproducibility of the experiment.

The etched surfaces of the specimens were also characterized by the same optical microscope using reflection light with differential interference contrast, DIC. For qualitative analysis, the spherulite size was measured according to the ASTM E112-10 standard for grain size determination [34].

\subsubsection{Differential scanning calorimetry, DSC}

The thermal properties were determined using DSC (TA Q20, TA instruments, Eschborn). An indium

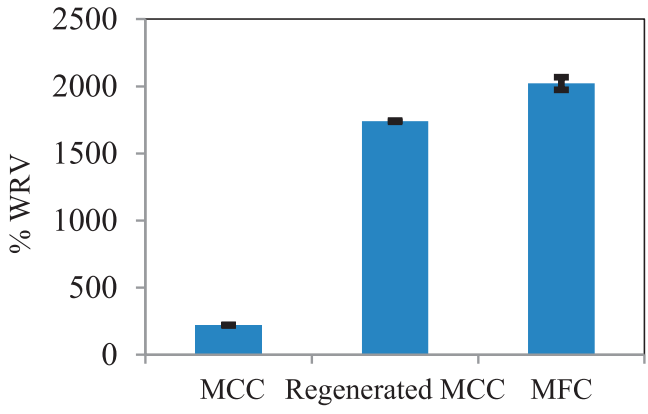

Figure 1: Water retention value of $\mathrm{MCC}$, regenerated MCC and MFC.

was used as a reference material to calibrate both the temperature scale and the melting enthalpy. The nitrogen gas was purged throughout the measurement. The weight of each specimen was always 5 to $10 \mathrm{mg}$. The specimen was placed in an aluminium pan and then was completely sealed with aluminium lid. The material was heated up from $0^{\circ} \mathrm{C}$ to $200^{\circ} \mathrm{C}$ at $10^{\circ} \mathrm{C} / \mathrm{min}$ of heating rate and then held at this temperature for 3 minutes to remove the thermal history. The specimen was then cooled from $200^{\circ} \mathrm{C}$ to $0^{\circ} \mathrm{C}$ at $10^{\circ} \mathrm{C} / \mathrm{min}$ of cooing rate. To minimize thermal degradation each specimen was used only one time. The crystallization temperature, $T_{c}$ was determined from the maximum of the exothermic peak. The degree of crystallinity was calculated using the following equation:

$\% X c=\left(\Delta H_{f} / \Delta H_{f}^{\circ} w\right) \times 100$

where $\Delta H_{f}$ is the heat of fusion of the specimen $(\mathrm{J} / \mathrm{g}), \Delta H^{\circ}$ is the heat of fusion of a theoretically $100 \%$ crystalline PP (209 J/g) [35] and $\mathrm{w}$ is the mass fraction of PP in the composite.

\section{Results and Discussion}

\subsection{MFC and organosilane treated MFC}

\subsubsection{Water retention value}

Percent WRVs of MCC, regenerated MCC and MFC as shown in Figure 1 are $222 \%, 1740 \%$ and $2022 \%$, respectively. In this case, WRV is related to the web-like structure of tiny microfibrils with high surface area. As seen in Figure 2, MFC exhibits web-like structure with the smallest in size, followed by regenerated 


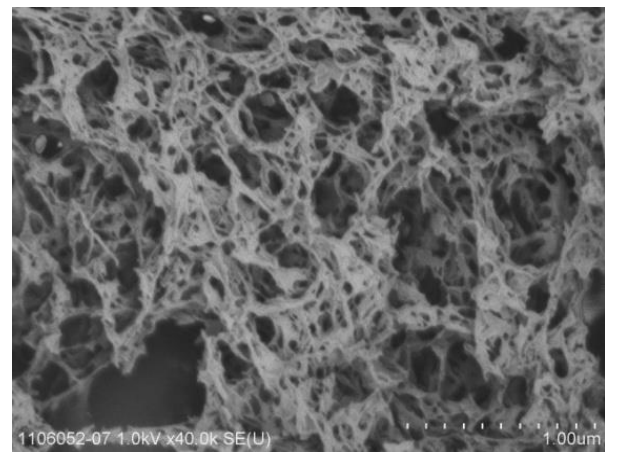

(a)

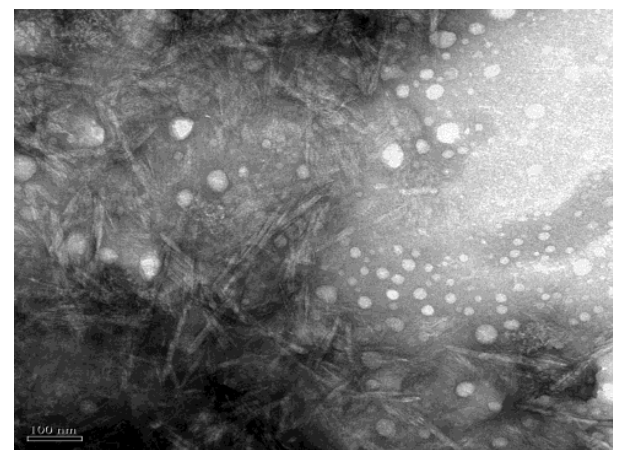

(b)

Figure 2: (a) FE-SEM micrograph and (b) TEM micrograph of MFC.

MCC and then MCC. The achievable web-like structure of MFC was due to the anti-coagulation effect of starch on retarding the agglomeration of cellulose microfibrills occurring in the precipitation step. As a result, The WRV of MFC is significantly higher than MCC as well as regenerated MCC. The plentiful availability of free hydroxyl groups on MFC surface facilitate MFC to present in the form of cellulose gel which is not observed in the case of regenerated MCC [36].

\subsubsection{Morphology of MFC andorganosilane treated MFC}

The morphology of MFC was investigated by FE-SEM and TEM shown in Figure 2a and 2b, respectively. The images indicate the web-like morphology of MFC. The diameter is found in the range of 10-20 nm and the length is more than $100 \mathrm{~nm}$. It is noticed that some fibrils agglomeration can be observed.

The morphology of organosilane treated MFC is found totally different from the virgin $\mathrm{MFC}$ as seen in Figure 3.

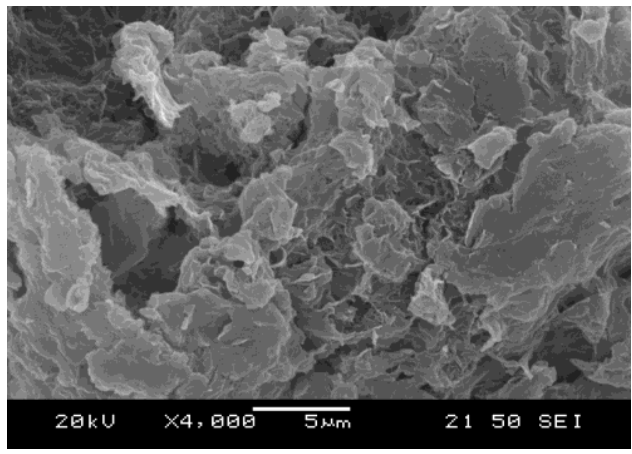

Figure 3: SEM micrograph of organosilane treated MFC.
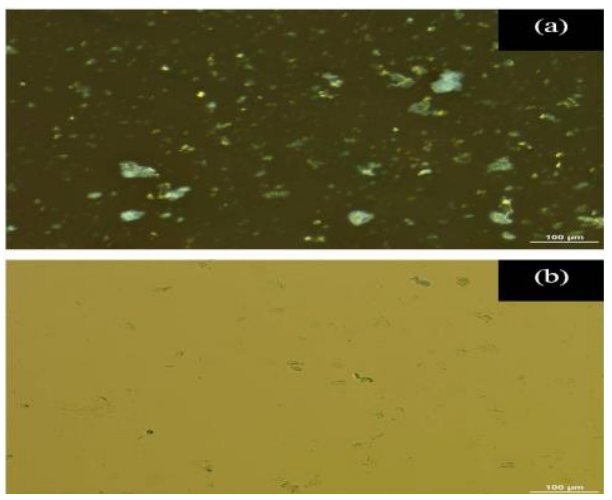

Figure 4: Optical micrographs of organosilane treated MFC a) reflection mode and b) transmission mode without polarize light.

The organosilane treated MFC is present in the dense agglomerate form. In order to find out what type of agglomeration, organosilane treated MFC was dispersed into toluene to observe the degree of swelling prior to optical microscopy observation as shown in Figure 4. Obviously, Figure 4a shows the swollen organosilane treated MFC in toluene, indicating the soft agglomeration behavior. When transmission mode without polarized light (Figure 4b) was employed, those swollen particles became transparent due to the good swelling ability of treated MFC in hydrophobic medium. Then, it was anticipated that organosilane treated microfibrills were preferably well-dispersed when incorporated into PP matrix.

\subsubsection{Particle size distribution}

The particle size distribution curve of organosilane treated MFC is shown in Figure 5. The diameter of 


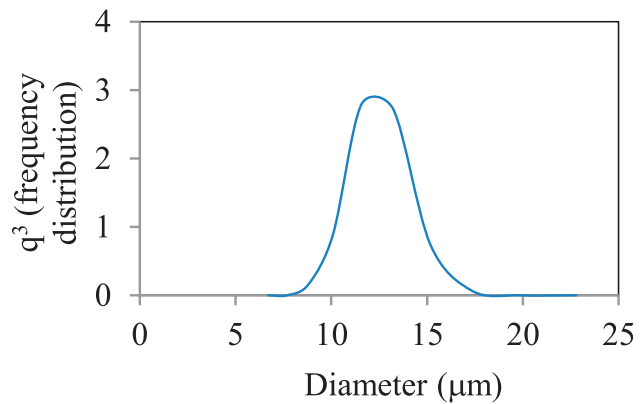

Figure 5: Particle size distribution curve of organosilane treated MFC.

organosilane treated MFC is found in the range of 8 to $17 \mu \mathrm{m}$ and the average diameter is around $11 \mu \mathrm{m}$. Micron-sized ranges of MFC are indicative of swell ability as well as soft agglomeration behavior of organosilane treated MFC.

\subsubsection{Functional groups}

The FTIR spectra of MFC and organosilane treated MFC are shown in Figure 6. The spectrum of MFC indicates the characteristic bands of cellulose. The broad band at 3,400 attributed to the stretching of the $\mathrm{O}-\mathrm{H}$ group and the $\mathrm{C}-\mathrm{H}$ stretching is at $2871 \mathrm{~cm}^{-1}$. The peak at $1640 \mathrm{~cm}^{-1}$ corresponds to the bending of bound water and the peak at $1363 \mathrm{~cm}^{-1}$ corresponds to $\mathrm{O}-\mathrm{H}$ bending. The peak at 1153, 1041 and $899 \mathrm{~cm}^{-1}$ is attributed to the $\mathrm{C}-\mathrm{O}$ stretching of cellulose, the vibration of $\mathrm{C}-\mathrm{O}-\mathrm{C}$ pyranose ring skeleton and the characteristic of $\beta$-glucosidic linkages between the sugar units, respectively [37].

TheFTIR spectra of organosilane treated MFC shows the characteristics peak of hexadecyltrimethoxysilane moiety. As a result of organosilane treatment, the cellulose $\mathrm{O}-\mathrm{H}$ stretching disappears, indicating the successful hydrophobicity modification. The two peaks at 2911 and $2846 \mathrm{~cm}^{-1}$ show the characteristic of symmetric and asymmetric vibration of the $\mathrm{CH}_{2}$ groups, respectively. The peaks at $860 \mathrm{~cm}^{-1}$ and $1080 \mathrm{~cm}^{-1}$ correspond to the $\mathrm{s}$ ymmetric and asymmetric stretching of $\mathrm{SiO}_{2}$ intertetrahedral, respectively. However, the vibration peak of Si-O-cellulose at 1000 to $1150 \mathrm{~cm}^{-1}$ shows up weakly [38].

\subsubsection{Crystallinity}

Figure 7 shows the XRD pattern of MCC, regenerated

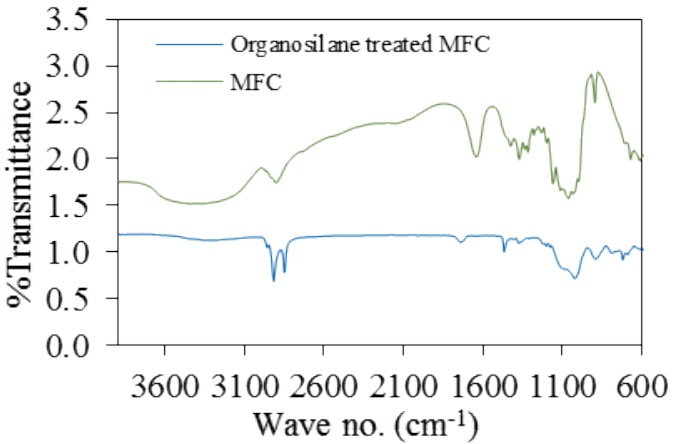

Figure 6: FT-IR spectra of MFC and organosilane treated MFC.

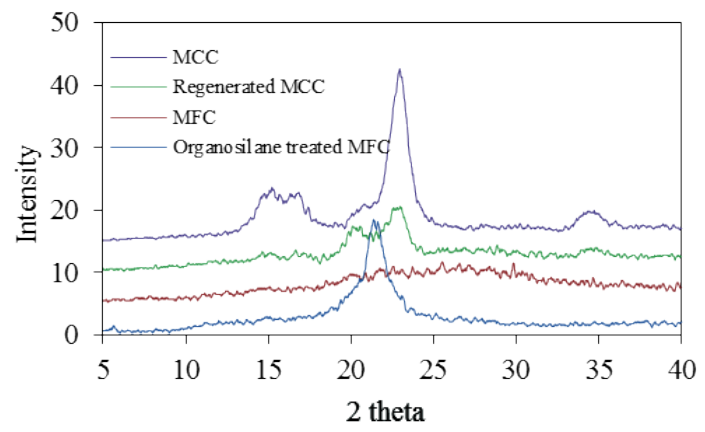

Figure 7: X-ray diffraction patterns of $\mathrm{MCC}$, regenerated MCC, MFC and organosilane treated MFC.

MCC, MFC and organosilane treated MFC, respectively. MCC shows the characteristic peaks of cellulose I crystal at $2 \theta=15.0^{\circ}, 16.3^{\circ}, 22.9^{\circ}$ and $34.1^{\circ}$ [39]. When compared to MCC, the diffraction peaks of regenerated MCC is shifted from $2 \theta=15-16^{\circ}$ to $19.8^{\circ}$, corresponding to the transformation of cellulose I crystal to cellulose II crystal [40]. Accordingly, the cellulose I crystal peaks decreases. XRD pattern of MFC reveals that the prepared MFC is partially amorphous arising from the anti-coagulating effect of starch molecules which obstructed the packing of cellulose chains occurring in the precipitation step. After being modified, organosilane treated MFC exhibits an increase in the crystallinity structure, evidenced by the strong crystalline peak at $2 \theta=21.3^{\circ}$. This phenomenon can be explained that the un-oriented MFC cellulose chain preferably underwent self-orientation (when condition was allowed) due to its crystalline characteristic by nature. As a result, the semi-crystalline MFC (before treatment) was transformed to crystalline MFC (after treatment). 


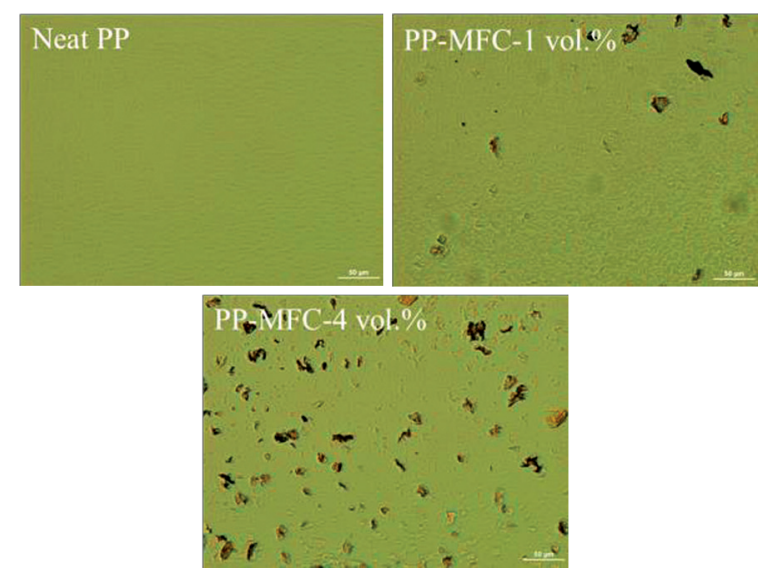

Figure 8: Optical micrographs of neat and MFC-filled $\mathrm{PP}$ composites (transmitted light mode); scale bar is $50 \mu \mathrm{m}$.

\subsection{PP/MFC composites}

\subsubsection{Dispersion of MFC fibrills}

Figure 8 shows optical micrographs of the materials under transmitted light. It reveals that an inhomogeneous distribution of MFC-agglomerates in the PP matrix filled with 1 vol.\% is clearly seen. However, a better distribution of MFC-agglomerates can be seen in the case of the 4 vol.\% MFC addition. The visible agglomerates are found in the average size of about $25 \mu \mathrm{m}$.

\subsubsection{Solidification process}

Figure 9 shows the development of the spherulitic structure of the different materials under polarized light in a hot stage. The pictures are taken during cooling at certain temperatures $\left(125.3^{\circ} \mathrm{C} ; 119.5^{\circ} \mathrm{C} ; 115.3^{\circ} \mathrm{C}\right)$.

It can be seen that first spherulites are visible at about $125^{\circ} \mathrm{C}$ just with the composites, whereas the neat $\mathrm{PP}$ is still fully molten. In addition, it can be recognized that higher MFC loading leads to a higher number of spherulites at the same temperature. At about $119^{\circ} \mathrm{C}$, the growth of spherulites occurs in all cases. However, the crystallization of the PP/MFC with 4 vol.\% of MFC composite is nearly finished; the higher the filler content the more the area covered by spherulites taken at the same temperature. Therefore, it seems to be a matter of fact that the MFC fibrills facilitate faster solidification. (a)
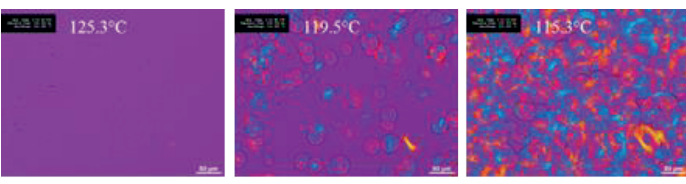

(b)
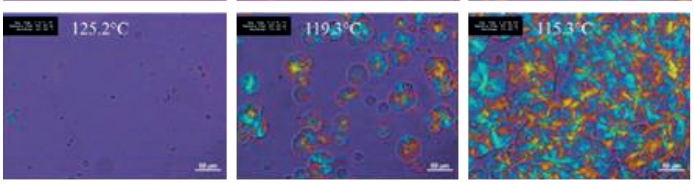

(c)
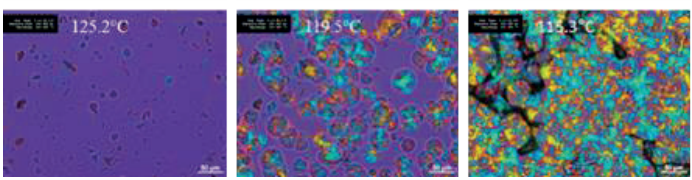

Figure 9: Solidification process of (a) neat PP, (b) PPMFC-1 vol.\% and (c) PP-MFC-4 vol.\%.

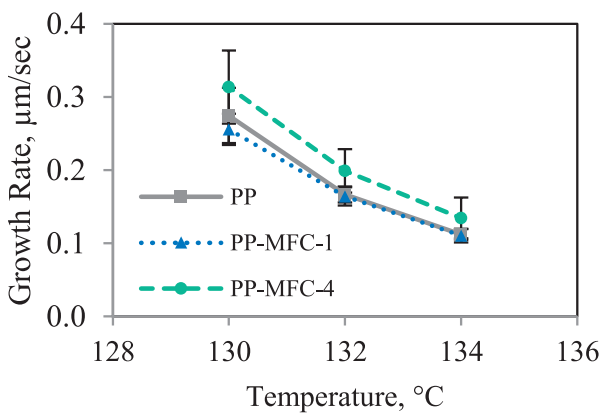

Figure 10: Spherulite growth rate of neat PP and MFCfilled PP composites.

\subsubsection{Isothermal spherulite growth rate}

Figure 10 shows the spherulite growth rate of the different materials. As expected, the spherulite growth rate depends directly on the crystallization temperature level. In all cases, an increase in crystallization temperature leads to a decrease in the spherulite growth rate. PP and the nanocomposite with 1 vol.\% MFC behave almost similar whereas the growth rate of the composite with 4 vol.\% MFC is higher. Basically, the spherulite growth rate depends on the crystallization temperature and the mobility of the polymer chain [41]. As described in the case of iPP grafted $\mathrm{SiO}_{2}$ nanoparticles, the shorter grafted iPP chain helped enhance the chain mobility, resulting in an increase in the spherulite growth rate at higher iPP grafted $\mathrm{SiO}_{2}$ loading [42]. Therefore, we assume also in this study that the chain mobility may be promoted by interaction between MFC particles and the PP chains. 


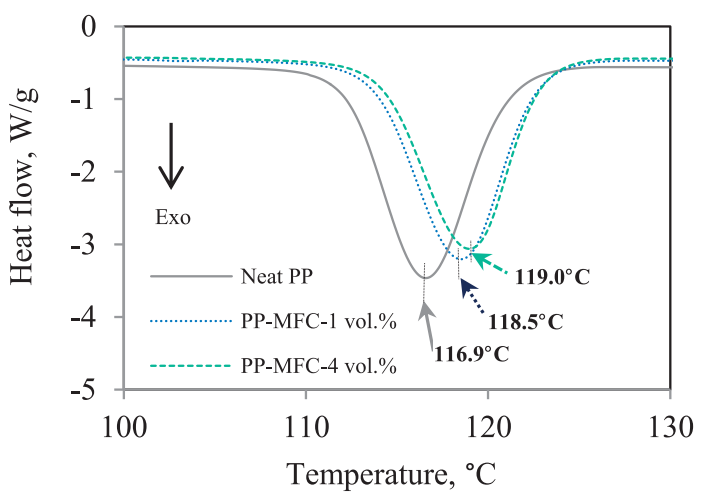

Figure 11: DSC exothermic curves of neat and MFCfilled PP composites.

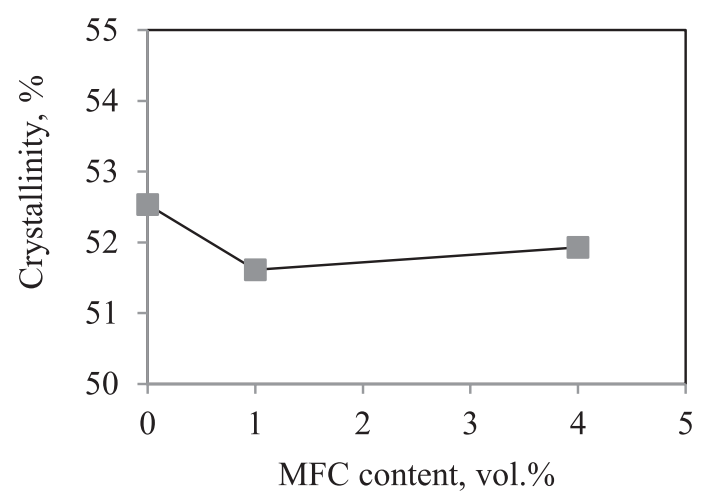

Figure 12: Degree of crystallinity of neat and MFCfilled PP composites.

\subsubsection{Crystallization properties}

Figure 11 shows the crystallization behavior measured by DSC. From these curves, it can clearly be stated that the crystallization temperature, $T_{c}$, shifts to a higher temperature with an increase in MFC loading. The neat PP exhibits a crystallization peak at $116.9^{\circ} \mathrm{C}$. An incorporation of $\mathrm{MFC}$ particles shifts the peak to $118.5^{\circ} \mathrm{C}$ at 1 vol.\% $\mathrm{MFC}$ and $119.0^{\circ} \mathrm{C}$ at 4 vol.\% MFC, respectively. The results confirm clearly that MFC acts as nucleating agent for PP, which is found in a similar manner to the previous finding $\left(\mathrm{PP} / \mathrm{SiO}_{2}\right.$ nanocomposite) [5].

Figure 12 plots the degree of crystallinity, $\mathrm{X}_{\mathrm{c}}$ of the materials versus the MFC-loading.

Actually, $X_{c}$ seems to be almost independent on the filler loading.
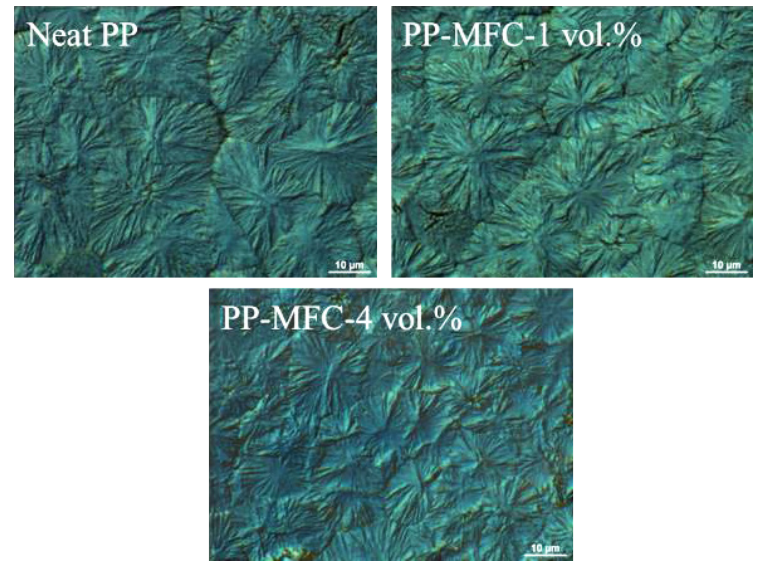

Figure 13: Spherulite structure of neat and MFC-filled PP composites.

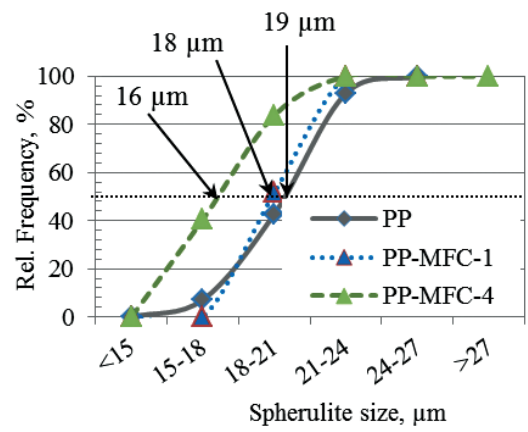

Figure 14: Cumulatedrelative frequency as a function of the spherulite diameter of neat PP and PP/MFC-composites.

\subsubsection{Spherulitic structure}

The optical micrographs in Figure 13 show the spherulitic structure of the different materials. The supermolecular structure of PP can be clearly recognized. The etching solution preferentially attacks the amorphous regions, leaving the crystalline branches essentially intact $[43,44]$. It is obvious that the spherulite size of PP filled with 4 vol.\% MFC is smaller compared to neat PP. However, the spherulite shape is almost the same in all cases.

The relative frequency of the spherulite diameter divided into 4 categories with $3 \mu \mathrm{m}$ increments from $15 \mu \mathrm{m}$ up to $28 \mu \mathrm{m}$ is plotted in Figure 14. The value $\mathrm{X}_{50,2}$ represents a characteristic value for the spherulite size. The index 50 is indicative of the median. The 2 indices represent that these values were determined based on two-dimensional images. 
Obviously, the median of the diameter distribution $\mathrm{X}_{50 / 2}$ shifts to a lower diameter range with an increase in MFC loading. When taking into consideration that the difference in the distribution of MFC is quite different (as seen in Figure 8) the nucleation density is reasonably responsible for a decrease in the spherulites size; the higher the filler loading the better the dispersibility of agglomerates as well as the higher number of nuclei [45]. These results shown in Table 1 are also found in-line to our previous work of $\mathrm{PP} / \mathrm{SiO}_{2}$ nanocomposites [6].

Table 1 summarizes the spherulite growth rate $\mathrm{dr} / \mathrm{dt} @ 132^{\circ} \mathrm{C}$, the temperature of the first visible solidification $T_{s 1}$, the crystallization temperature $T_{c}$, the degree of crystallinity $\mathrm{xc}$ and the resulting mean spherulite size $\mathrm{X}_{50,2}$ of PP and the PP/MFC-composites.

Table 1: Characteristic data of the morphology

\begin{tabular}{|l|c|c|c|c|c|}
\hline & $\begin{array}{c}\mathbf{d r} / \mathbf{d t}, \\
\boldsymbol{\mu m} / \mathbf{s}\end{array}$ & $\begin{array}{c}\mathbf{T}_{\mathbf{s}}, \\
{ }^{\circ} \mathbf{C}\end{array}$ & $\begin{array}{c}\mathbf{T}_{\mathbf{c}}, \\
{ }^{\circ} \mathbf{C}\end{array}$ & $\begin{array}{c}\mathbf{x}_{\mathbf{c}}, \\
\mathbf{\%}\end{array}$ & $\begin{array}{c}\mathbf{d S}\left(\mathbf{X}_{\mathbf{5 0 , 2}, 2}\right) \\
\boldsymbol{\mu m}\end{array}$ \\
\hline PP & 0.17 & 128.5 & 116.9 & 52.5 & 19 \\
\hline PP/MFC-1 & 0.16 & 129.8 & 118.5 & 51.6 & 18 \\
\hline PP/MFC-4 & 0.20 & 131.5 & 119.0 & 51.9 & 16 \\
\hline
\end{tabular}

\section{Conclusions}

MFC could be prepared from a dissolution/ precipitation technique by dissolution of MCC in cooled $\mathrm{NaOH} /$ Urea solution and then precipitation in an $\mathrm{HCl}$ bath using starch as an anti-coagulating agent. The morphology of MFC exhibited a web-like structure and a diameter in the range of 10-20 nm. The water retention value of MFC was higher than MCC and regenerated $\mathrm{MCC}$ due to the smaller diameter and higher surface area. The XRD pattern of MFC indicated the partially amorphous structure because of the imperfect orientation of cellulose chains obstructed by starch molecule occurring in the precipitation step. The organosilane treated MFC showed hydrophobic characteristics with the disappearance of the original cellulose hydroxyl group and bound water. Its crystallinity increased when compared to virgin MFC. However, the modified MFC exhibited the agglomeration with layer structure arising from the packing of microfibrils.

The effect of the addition of MFC particles on the morphology and crystallization of PP was examined by optical microscopy and thermal analysis. The results showed clearly that MFC particles facilitate faster solidification of the material, especially at higher filler loading. Moreover, the addition MFC accelerated the spherulite growth rate of PP. Based on the significant nucleation ability of MFC surfaces, the crystallization temperature $\left(\mathrm{T}_{\mathrm{c}}\right)$ increased with an increase MFC loading, leading to faster crystallization. However, the degree of crystallinity was independent on the filler loading despite the decrease in spherulite size with an increase in MFC loading. In summary it could be stated that the addition of MFC definitely led to faster solidification which might enable shorter cycle times, resulting in lower processing cost in polymer processing.

\section{Acknowledgments}

The authors would like to thank Ratchadaphiseksomphot Endowment Fund of Chulalongkorn University (RES560530023-AM), the Royal Golden Jubilee Ph.D. program, the OPTIMAS/Carl-Zeiss Ph.D. program and the DAAD-TRF Project based Personnel Exchange Program (PPP 2013) for the support of this work. FE-SEM and SEM analysis were supported by Prof. Kobayashi from Nagaoka University Laboratory, Japan and Prof. Kopnarski and Mrs. Wagner from the Institute for Surface and Thin Film Analysis IFOS, Kaiserslautern, Germany. We also thank Prof. Ripperger, University of Kaiserslautern, Chair of Particle Process Engineering, for the support regarding the particle size distribution analysis.

\section{References}

[1] Z. Zhou, S. Wang, L. Lu, Y. Zhang, and Y. Zhang, "Isothermal crystallization kinetics of polypropylene with silane functionalized multi-walled carbon nanotubes," Journal of Polymer Science: Part B: Polymer Physics, vol. 45, pp. 1616-1624, 2007.

[2] C. M. Chan, J. Wu, J. X. Li, and Y. K. Cheung, "Polypropylene/calciumcarbonate nanocomposites," Polymer, vol. 43, pp. 2981-2992, 2002.

[3] M. Altan and H. Yildirim, "Mechanical and morphology properties of polypropylene and high density polyethylene matrix composites reinforced with surface modified nano sized $\mathrm{TiO}_{2}$ particles," World Academy of Science, Engineering and Technology, vol. 46, pp. 289-294, 2010.

[4] T. H. Zhou, W. H. Ruan, Y. L. Mai, M. Z. Rong, 
and M. Q. Zhang, "Performance improvement of nano-silica/polypropylene composites through in-situ cross-linking approach," Composites Science and Technology, vol. 68, pp. 2858-2863, 2008.

[5] A. K. Schlarb, D. N. Suwitaningsih, M. Kopnarski, and G. Niedner-Schatteburg, "Supermolecular morphology of polypropylene filled with nanosized silica," Journal of Applied Polymer Science, vol. 131(1), pp. 39655(1)-(8), 2014, DOI: 10.1002/app.39655

[6] B. Suksut and A. K. Schlarb, "Analysis of the morphology of injection molded plates of PP/ $\mathrm{SiO}_{2}$-nanocomposites," Journal of Plastics Technology, vol. 10, pp. 68-85, 2014.

[7] Y. Ruksakulpiwat, N. Suppakarn, W. Sutapun, and W. Thomthong, "Vetiver-polypropylene composites: Physical and mechanical properties," Composites Part A: Applied Science and Manufacturing, vol. 38, pp. 590-601, 2007.

[8] C. Saujanya and S. Radhakrishnan, "Structure development and properties of PET fibre filled PP composites," Polymer, vol. 42, pp. 4537-4548, 2001.

[9] A. Faisal and H. Salmah, "Mechanical and Thermal Properties of Compatibilized Waste Office White Paper-Filled Low-Density Polyethylene Composites," Journal of Thermoplastic Composite Materials, vol. 25, pp. 193-207, 2012.

[10] C.S. Wu and H.T. Liao, "PolycaprolactoneBased Green Renewable Ecocomposites Made from Rice Straw Fiber: Characterization and Assessment of Mechanical and Thermal Properties," Industrial \& Engineering Chemist Research, vol.51, pp. 3329-3337, 2012.

[11] X.Q. Li, L.P. He, H.Y.Zhou, W.J. Li, and W.K. Zha, "Influence of silicone oil modification on properties of ramie fiber reinforced propylene composites," Carbohydrate Polymers, vol. 87, pp. 2000-2004, 2012.

[12] D.K. Chen, J. Li, and J. Ren, "Biocomposites based on ramie fibers and poly(L-lactic acid) (PLLA): morphology and properties," Polymer for Advanced Technologies, vol. 23, pp. 198-207, 2012.

[13] S. Chuayjuljit, S. Su-Uthai, C. Tunwattanaseree, and S. Charuchinda, "Preparation of Microcrystalline Cellulose from Waste-Cotton Fabric for Biodegradability Enhancement of Natural Rubber
Sheets," Journal of Reinforced Plastic and Composites, vol. 28, pp. 1245-1254, 2009.

[14] Y. Xie, C. A. S. Hill, Z. Xiao, H. Militz, and C. Mai, "Silane coupling agents used for natural fiber/ polymer composite: A review," Composite: Part A, vol. 41, pp. 806-819, 2010.

[15] M. Abdelmouleh, S. Boufi, A. B. Salah, M. N. Belgacem, and A. Gandini, "Interaction of Silane Coupling Agents with Cellulose," Langmuir, vol. 18, pp. 3203-3208, 2002.

[16] P. Thumanukitcharoen, S. Limpanart, and K. Srikulkit, "Preparation of Organosilane Treated Microcrystalline (SiMCC) and SiMCC/ Polypropylene Composites," Journal of Metals, Materials and Minerals, vol. 22(1), pp. 13-19, 2012.

[17] A. Ashori and A. Nourbakhsh, "Performance properties of microcrystalline cellulose as a reinforcing agent in wood plastic composites," Composites: Part B, vol. 41, pp. 578-581, 2010.

[18] S. Iwamoto, S. Yamamoto, S. Lee, and T. Endo, "Mechanical properties of polypropylene composites reinforced by surface-coated microfibrillated cellulose," Composites: Part A, vol. 59, pp. 26-29, 2014.

[19] A. N. Nakagaito, A. Fujimura, T. Sakai, Y. Hama, and H. Yano, "Production of microfibrillated cellulose (MFC)-reinforced polylactic acid (PLA) nanocomposites from sheet obtained by a papermaking-like process," Composites Science and Technology, vol. 69, pp. 1293-1297, 2009.

[20] J. Lu, T. Wang, and L. T. Drzal, "Preparation and properties of microfibrilaated cellulose polyvinylalcohol compositematerials," Composites: Part A, vol. 39, pp. 738-746, 2008.

[21] K.L. Spence, R.A. Venditti, Y. Habibi, O.J. Rojas, and J.J. Pawlak, "The effect of chemical composition on microfibrillar cellulose films from wood pulps: Mechanical processing and physical properties," Bioresource Technology, vol. 101, pp. 5961-5968, 2010.

[22] N. Lavoine, I. Desloges, A. Dufresne, and J. Bras, "Microfibrillated cellulose-Its barrier properties and applications in cellulosic materials: a review," Carbohydrate Polymer, vol. 90, pp. 735764, 2012.

[23] I. Siro and D. Plackett, "Microfibrillated cellulose and new nanocomposites materials: a 
review," Cellulose, vol. 17, pp. 459-494, 2010.

[24] T. Heinze and T. Liebert, "Unconventional method in cellulose functionalization," Progress in Polymer Science, vol. 26, pp. 1689-1762, 2001.

[25] X. Luo and L. Zhang, "New solvents and functional materials prepared from cellulose solutions in alkali/urea aqueous system," Food Research International, vol. 52, pp. 387-400, 2013.

[26] S. Zhang, F. Li, J. Yu, and Y. Hsieh, "Dissolution behavior and solubility of cellulose in $\mathrm{NaOH}$ complex solution," Carbohydrate Polymers, vol. 81, pp. 668-674, 2010.

[27] D. Ruan, L. Zhang, Y. Mao, M. Zeng, and X. Li, "Microporous membranes prepared from cellulose in $\mathrm{NaOH} /$ thiourea aqueous solution," Journal of Membrane Science, vol. 241, pp. 265274, 2004.

[28] H. Jin, C. Zha, and L. Gu, "Direct dissolution of cellulose in $\mathrm{NaOH} /$ thiourea/urea aqueous solution," Carbohydrate Research, vol. 342, pp. 851-858, 2007.

[29] H. Qi, T. Liebert, F. Meister, and T. Heinze, "Homogeneous carboxymethylation of cellulose in the $\mathrm{NaOH}$ /urea aqueous solution," Reactive \& Functional polymers, vol. 69, pp. 779-784, 2009.

[30] U. Ratanakamnuan, D. Atong, and D. Aht-Ong, "Cellulose esters from waste cotton fabric via conventional and microwave heating," Carbohydrate Polymers, vol. 87, pp. 84-94, 2012.

[31] D.C. Bassett and R.H. Olley, "On the lamellar morphology of isotactic polypropylene spherulites," Polymer, vol. 25, pp. 935-943, 1984.

[32] M.M. Shahin, R. H. Olley, and M. J. Blissett, "Refinement of etching techniques to reveal lamellar profiles in polyethylene banded spherulites," Journal of Polymer Science Part B: Polymer Physics, vol. 37, pp. 2279-2286, 1999.

[33] N. Jacquet, C. Vanderghem, S. Danthine, N. Quiévy, C. Blecker, J. Devaux, and M. Paquot, "Influence of steam explosion on physicochemical properties and hydrolysis rate of pure cellulose fibers," Bioresource Technology, vol. 121, pp. 221-227, 2012.

[34] N.N., ASTM E112-10 Standard Test Methods for Determining Average Grain Size, 2010.

[35] M. Garcia, G. V. van Vliet, S. Jain, B. A. G.
Schrauwen, A. Sarkissov, W. E. van Zyl, and B. Boukamp, "Polypropylene/SiO2 nanocomposites with improved mechanical properties," Reviews on Advanced Materials Science, vol. 6, pp. 169175, 2004.

[36] J. Zhang, H. Somg, L. Lin, J. Zhuang, C. Pang, and S. Liu, "Microfibrillated cellulose from bamboo pulp and its properties," Biomass and Bio Energy, vol. 39, pp. 78-83, 2012.

[37] W.Y. Li, A.X. Jin, C.F. Liu, R.C. Sun, A.P. Zhang, and J.F. Kenedy, "Homogeneous modification of cellulose with succinic anhydride in ionic liquid using 4-dimethylaminopyridine as a catalyst," Carbohydrate Polymers, vol. 78, pp. 389-395, 2009.

[38] S. Sequeira, D.V. Evtuguin, I. Portugal, and A.P. Esculcas, "Synthesis and characterization of cellulose/silica hybrids obtained by heteropoly acid catalysed sol-gel process," Material Science and Engineering: C, vol. 27, pp. 172-179, 2007.

[39] E. Fortunati, M. Peltzer, I. Armentano, L. Torre, A. Jiménez, and J.M. Kenny, "Effect of modified cellulose nanocrystals on barrier and migration properties of PLA nanobiocomposites," Carbohydrate Polymers, vol.90,pp.948-956, 2012.

[40] H. Qi, C. Chang, and L. Zhang, "Effects of temperature and molecular weight on dissolution of cellulose in $\mathrm{NaOH} /$ urea aqueous solution," Cellulose, vol. 15, pp. 779-787, 2008.

[41] R. J. Young and P. A. Lovell, Introduction to Polymers, London: Chapman \& Hall, 1991.

[42] Y. Fukuyama, T. Kawai, S. I. Kuroda, M. Toyonaga, T. Taniike, and M. Terano, "The effect of the addition of polypropylene grafted $\mathrm{SiO}_{2}$ nanoparticle on the crystallization behavior of isotactic polypropylene," Journal of Thermal Analysis and Calorimetry, vol. 113, pp. 15111519, 2013, DOI: 10.1007/s10973-012-2900-7

[43] L. D. Sawyer, D. T. Grubb, and G. F. Meyers, Polymer Microscopy, New York: Springer, 2008.

[44] J. S. Mijovic and J. A. Koutsky, "Etching of Polymeric Surface: A Review," Polymer-Plastics Technology and Engineering, vol. 9, pp. 139-179, 1977.

[45] Y. He and Y. Inoue, " $\alpha$-Cyclodextrin-Enhanced Crystallization of Poly(3- Hydroxybutyrate)," Biomacromolecules, vol. 4, pp. 1865-1867, 2003. 